\title{
研究論交
}

\section{Countercurrent Computation on Trinitrato Complex of Nitrosylruthenium in the Primary Separation Plant of Reactor Fuel Processing}

\author{
再処理プラントにおけるルテニウムストリッピングの化学工学的考察 \\ By Masao TAKIGISHI*
}

\begin{abstract}
Differential equations based on the kinetics of the interchange between organic and aqueous phase have been developed to the counter current computation on stripping and extraction of trinitrato complex of nitrosylruthenium. The application of obtained solutions to tha process could express sufficiently the performance of mixer settler system and it has been also suggested that the mixing time should be well decided to give the reasonable change of concentration in each section. It is also possible to analyse the ruthenium recycling in the extraction section and the feed stage as previously suggested by Fletcher ${ }^{(4)}$.
\end{abstract}

\section{General}

Although many papers on experimental studies $^{(1) \sim(9)}$ of trinitrato complex of nitrosylruthenium have been published, no details of counter currert computation relevant to the extraction and the stripping process have been seen anywhere. It is likely that even if such a computation as this had been already well established, any papers on this subject might be still classified.

Without this computation, it might be quite difficult to analyse the experimental data obtained from the counter current miniature extractor run and further to design any mixer settler system for this use.

Reaction rate constants of RuNO trinitrato complexes in aqueous phase and between aqueous and organic phase have been measured by Jerkins, et al. and Fletcher, et $a l^{(9)}$.

It is quite possible to introduce some differential equations from the above rate constants, which direct solutions should be led to the parallel flow system of mixer settler.

With the proper modification of these solutions and their modified application, it was also possible to compute the change of concentration of trinitrato complex in the counter current system, in accordance with the length of mixing time in each mixer settler bank. Fletcher ${ }^{(9)}$ has suggested the following scheme summarizing the reactions in aqueous and organic phase.

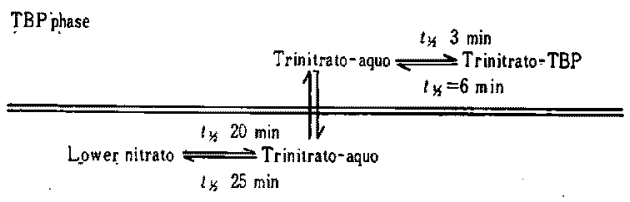

Aqueous phase

It is also reported that the transmission of trinitrato-aquo between organic and aqueous phase might proceed in a few seconds. At equilibrium it is computed from the rate constants that the ratio of concentration, trinitrato-aquo/trinitrato-TBP in organic phase should be 0.5 .

In proceeding of computation there always exists the tendency to keep trinitrato-aquo in organic phase to a lesser extent so that the concentration of trinitrato-aquo in organic phase might be neglected and all trinitrato-

* 潼岸正夫。Atomic Fuel Corp.（原子燃料公社調 育室) 
aquo might be considered to be in aqueous phase, since the concentration of trinitratoaquo in both phases would change slowly with the rate-constant from mononitrato to trinitrato in extraction section and trinitratoTBP might change almost directly into trinitrato-aquo in aqueous phase on account of a. remarkably reduced partition coefficient computed from uranium saturation of TBP in stripping section.

\section{Extraction of trinitrato complex of nitrosylruthenium}

$$
\begin{aligned}
& \text { Lower nitrato } \underset{K_{2}}{\stackrel{K_{2}^{\prime}}{\rightleftharpoons}} \text { Trinitrato-aquo } \\
& \stackrel{\frac{K_{1}{ }^{\prime}}{\rightleftharpoons}}{\underset{K_{1}}{\rightleftharpoons}} \text { Trinitrato-TBP }
\end{aligned}
$$

The direction of reaction should be decided with the difference between the instantaneous distribution coefficient and the equilibriated distribution coefficient in this case.

In the extraction section, the uranium saturation of TBP should occur at the end of extraction or the feed stage as computed afterwards, therefore the equilibriated distribution coefficient should be kept rather high as shown in Fig. 9 so that trinitrato-aquo should be always transferred to the organic phase.

On the contrary, in the stripping section, the uranium saturation of TBP should repress the equilibriated distribution coefficient to the extremely reduced value so that trinitrato-TBP should be always stripped to the aqueous phase. Therefore,

$$
\begin{aligned}
& -\frac{d C_{D}}{d t}=K_{2}^{\prime} C_{D}, K_{2}^{\prime}=0.034 \mathrm{~min}^{-1}\left(t_{1 / 2}=20 \mathrm{~min}\right) \\
& \frac{d C_{A}}{d t}=K_{1}^{\prime} C_{B}, K_{1}^{\prime}=0.24 \mathrm{~min}^{-1} \quad\left(t_{1 / 2}=3 \mathrm{~min}\right)
\end{aligned}
$$

$$
\frac{d C_{B}}{d t}=K_{2}^{\prime} C_{D}-K_{1}^{\prime} C_{B}
$$

The solution of Eq. (1)

$$
C_{D}=C_{D D} \mathrm{e}^{-K_{2}^{\prime} t}
$$

where $C_{D 0}$ is the initial concentration of $C_{D}$.

The solution of Eq. ( 3 ) becomes

$$
C_{B}=\left[C_{B 0}-\frac{K_{2}^{\prime} C_{D 0}}{K_{1}^{\prime}-\overline{K_{2}}}\left\{1-\mathbf{e}^{\left(K_{1}^{\prime}-K_{2}^{\prime}\right) t}\right\}\right] \mathbf{e}^{-K_{1}^{\prime} t}
$$

where $C_{B 0}$ is the initial concentration of $C_{B}$ and if we put $C_{D 0} / C_{B 0}=K$,

$$
C_{B}=C_{B 0}\left[1-\frac{K K_{2} t}{K_{1}-K_{2}^{\prime}}\left\{1-\mathbf{e}^{\left(K_{1}^{\prime}-K_{2}^{\prime}\right) t}\right\}\right] \mathbf{e}^{-K_{1} t}
$$

where

$$
\frac{K_{2}^{\prime}}{K_{!}{ }^{\prime}-K_{2}^{\prime}}=\frac{0.034}{0.24-0.034}=0.165
$$

In accordance with the determination method, some difference might be perceived on the relative concentration of RuNO nitrato complexes. However, $K$ has been computed to 5.2 and 5.3 respectively for aqueous nitric acidity $3 \mathrm{~N}$ from two experimental data ${ }^{(5)(6)}$ obtained by solvent extraction method.

It also might favor $K=6$ that there should exist the tendency to keep the equilibrium between concentrations of RuNO nitrato complexes in aqueous phase.

Therefore, $K$ might be put as 6 for aqueous nitric acidity $3 \mathbf{N}$.

$$
\frac{K K_{2}{ }^{\prime}}{K_{1}-K^{2}}=(0.165)(6) \fallingdotseq 1
$$

and

$$
C_{B}=C_{B 0} \mathrm{e}^{-K_{2}^{\prime} t}
$$

It is a remarkable feature of counter current system in this case that a rather complicated equation has been changed to a simple one (5) and the changing rate of trinitrato-aquo in aqueous phase has proved to be the same to the transformation rate from mononitrato to trinitrato complex in aqueous phase. This quite agrees with Fletcher's expression ${ }^{(3)}$ that in extraction section trinitrato-aquo in aqueous phase has been slowly changed to trinitrato-TBP in organic phase.

Solution of Eqs. (3) and (7)

$$
C_{A}=C_{A 0}+\frac{K_{1}^{\prime}}{K_{2}^{\prime}} C_{B 0} \quad\left(1-\mathbf{e}^{-K_{2}^{\prime} t}\right)
$$

where $C_{\Delta 0}$ is the initial concentration of $C_{A}$. 
In each mixer settler bank the change of concentration of the trinitrato-aquo in aqueous phase is computed by putting the mixing time $M$ to $t$ in Eq. (5) and the change of concentration of trinitrato-TBP in organic phase is also computed from Eq. (6) by the same way.

Fig. 1 might make the application of Eqs. (5) and ( 6 ) to counter current system more understandable.

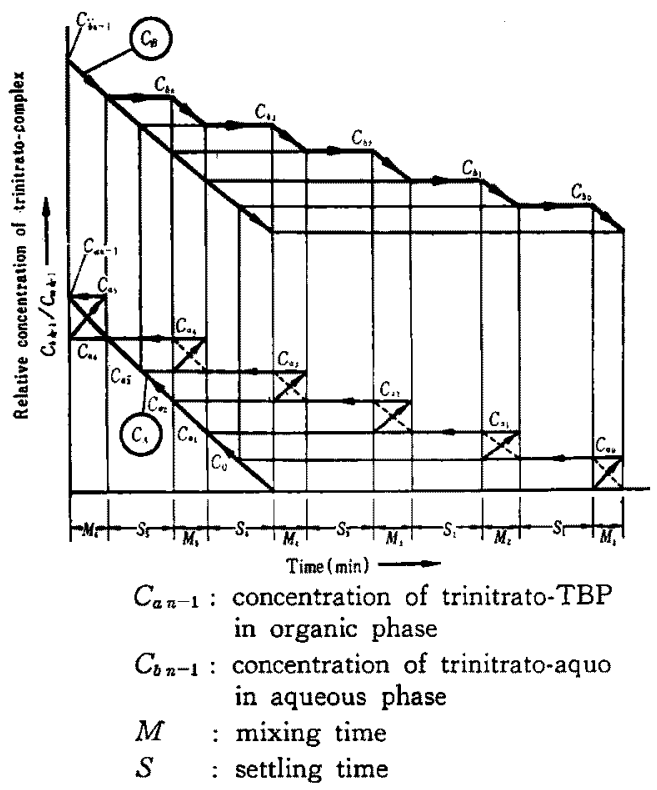

Fig. 1 The relative concentrations of trinitrato complex $v$ s. mixing and settling time

In Fig. 1 the curve $C_{A}$ and $C_{B}$ might be obtained by putting settling time $=0$ and $C_{b o}$ is computed by putting $t=$ total mixing time $-M_{1}$, into Eq. ( 5 ) and $C_{a 0}$ is computed by putting $C_{B 0}=C_{B 0} \cdot C_{A 0}=0$ and $t=M_{1} \min$ into Eq. (6).

Subsequently $C_{a 1}, C_{a 2}, \cdots \cdots \cdots$ and $C_{a n^{-1}}$ corresponding to $C_{t 1}, C_{b z}, \cdots \cdots \cdots$ and $C_{b n^{-1}}$ might be computed by the same way from Eqs. (5) and ( 6 ). The stepwise curves in Fig. 1 might be obtained by adding settling time to mixing time and the dotted lines express the apparent change of $C_{a} v s$, time.

Normally, $M_{1}=M_{2}, \cdots \cdots \cdots=M$

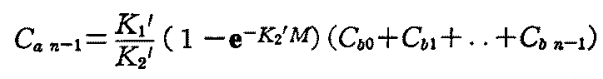

Therefore, $C_{a}$ changes as the graph in Fig. 2.

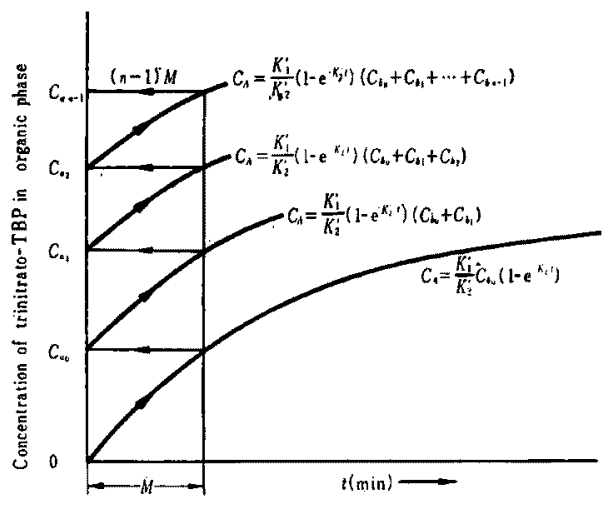

Fig. 2 Concentration of trinitrato-TBP in organic phase vs. mixing time

In Eq. (7), if we put

$$
\begin{gathered}
C_{b 0}=C_{b n-1} \mathbf{e}^{-(n-1) K_{2}{ }^{\prime} M} \\
C_{b 1}=C_{b n-1} \mathbf{e}^{-(n-2) K_{2} M} \\
\cdots \cdots \cdots \\
\frac{C_{a n-1}}{C_{b n-1}}=\frac{K_{1}{ }^{\prime}}{K_{2}{ }^{\prime}}\left(1-\mathbf{e}^{\left.-K_{2}{ }^{\prime} M\right)}\left\{1+\mathbf{e}^{-K_{2}{ }^{\prime} M}+\mathbf{e}^{-2 K_{2}{ }^{\prime} M}+\right.\right. \\
\left.\cdots \cdots+\mathbf{e}^{-(n-1) K_{2}{ }^{\prime} M}\right\} \quad \text { ( 8) }
\end{gathered}
$$

The relative concentration,

Concentration of trinitrato-TBP in organic phase Concentration of trinitrato-aquo in aqueous phase

$$
=\frac{C_{a n-1}}{C_{0 n-1}}
$$

has been expressed as a function of mixing time/bank and number of stage by Eq. ( 8 ).

The number of stage in extraction section required for the sufficient recovery of uranium

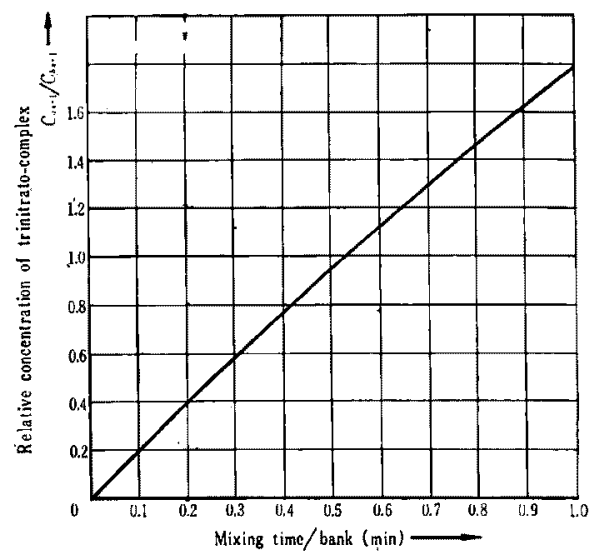

Fig. 3 The relative concentration of trinitrato complex vs. mixing time/bank (Number of stage : 10) 
and plutonium might be normally computed to 10 and the relative concentration vs. mixing time/bank has been computed as Fig. 3, from $\mathrm{Eq}$. (8).

\section{Stripping of trinitrato complex of nitrosylruthenium}

$$
\begin{aligned}
-\frac{d C_{A}}{d t} & =K_{1} C_{A}, K_{1}=0.12 \quad\left(t_{1 / 2}=6 \mathrm{~min}\right) \\
\frac{d C_{D}}{d t} & =K_{2} C_{B}, K_{2}=0.028 \quad\left(t_{1 / 2}=25 \mathrm{~min}\right) \\
\frac{d C_{B}}{d t} & =K_{1} C_{A}-K_{2} C_{B}
\end{aligned}
$$

Solution of Eq. (9)

$$
C_{\Delta}=C_{\Delta 0} \mathrm{e}^{-K_{1} t}
$$

where $C_{\Delta}$ is the initial concentration of $C_{A}$.

Solution of Eqs. (11) and (12)

$$
C_{B}=\left[C_{B 0}+\frac{K_{1} C_{A}}{K_{1}-K_{2}}\left\{1-\mathbf{e}^{-\left(K_{1}-K_{2}\right) t}\right\}\right] \mathrm{e}^{-K_{2} t}
$$

where $C_{B 0}$ is the initial concentration of $C_{B}$.

The following equation might be introduced by the same method to extraction.

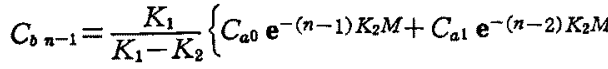

$$
\begin{aligned}
& \left.+\cdots \cdots+C_{a n-1}\right\}\left\{1-\mathrm{e}^{-\left(K_{1}-K_{2}\right) M}\right\} \mathbf{e}^{-K_{2} M}
\end{aligned}
$$

where $M$ is the mixing time of one mixer settler bank.

Also Fig. 4 might make the application of Eqs. (12) and (13) to counter current system more readily understandable.

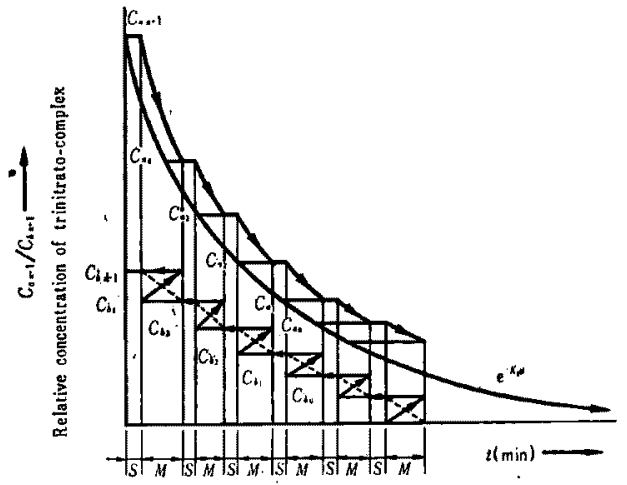

$$
\begin{aligned}
& C_{a n-1}: \text { concentration of trinitrato-TBP } \\
& C_{\partial n-1} \text { : concentration of trinitratoaquo } \\
& \text { in aqueous phase } \\
& M \quad \text { : mixing time } \\
& S \text { : settling time }
\end{aligned}
$$

Fig. 4 The relative concentrations of trinitrato complex vs. mixing and settling time in stripping

In Eq. (14), if we put $C_{a 0}=C_{a n-1} \mathrm{e}^{-(n-1) K_{1} M,}, \quad C_{a 1}=C_{a n-1} \mathbf{e}^{-(n-2) K_{1} M}, \cdots \ldots \ldots$

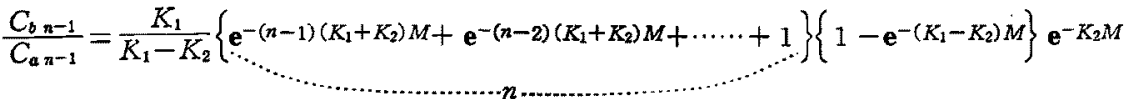

$$
\begin{aligned}
& =\frac{K_{1}}{K_{1}-K_{2}}\left\{1-\mathbf{e}^{-n\left(K_{1}+K_{2}\right) M}\right\} \frac{1-\mathbf{e}^{-\left(K_{1}-K_{2}\right) M}}{1-\mathbf{e}^{-\left(K_{1}+K_{2}\right) M}} \mathbf{e}^{-K_{2} M}
\end{aligned}
$$

The relative concentration in stripping section has been expressed as a function of mixing time/bank $M$ and number of stage $n$ by Eq. (15). Two examples of relative concentration computed from $\mathrm{Eq}$. (15) have been illustrated in Figs. 5 and 6.

It should be noted that the relative concentrations of trinitrato complex have been computed for the equal volume of organic and aqueous phase and the appropriate correlation should be required for the different ratio of organic to aqueous phase.

The most significant illustration of relative concentrations is Fig. 7 in which the relative concentrations vs. mixing time/bank have been computed for 10 bank mixer settler.

It might be clearly understood by the comparison of relative concentrations in Figs. 3 and 7 that the mixing time in stripping section should be remarkably prolonged to $2 \sim 3 \mathrm{~min}$ /bank to give the relative concentration 0.75 $\sim 0.8$ in comparison with the rather short mixing time $/$ bank $0.1 \sim 0.2 \mathrm{~min} / \mathrm{bank}$ to keep the relative concentration $0.2 \sim 0.4$ in extraction section. The correlation for the different ratio of organic phase to aqueous phase and effects of TBP saturation with uranium should be also applied to the computation on the continuous change of relative concentration $v s$. mixing time in stripping and extrac- 


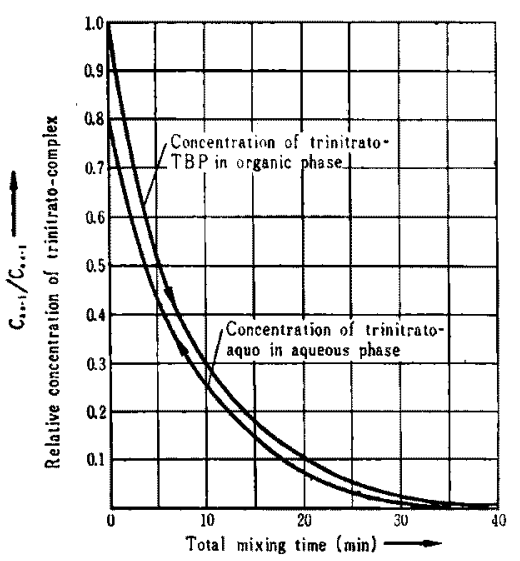

Total mixing time: $35 \mathrm{~min}$ Mixing time/bank: $3.5 \mathrm{~min}$ Number of stage: 10

Fig. 5 The relatiye concentration of trinitrato-complex vs, total mixing time

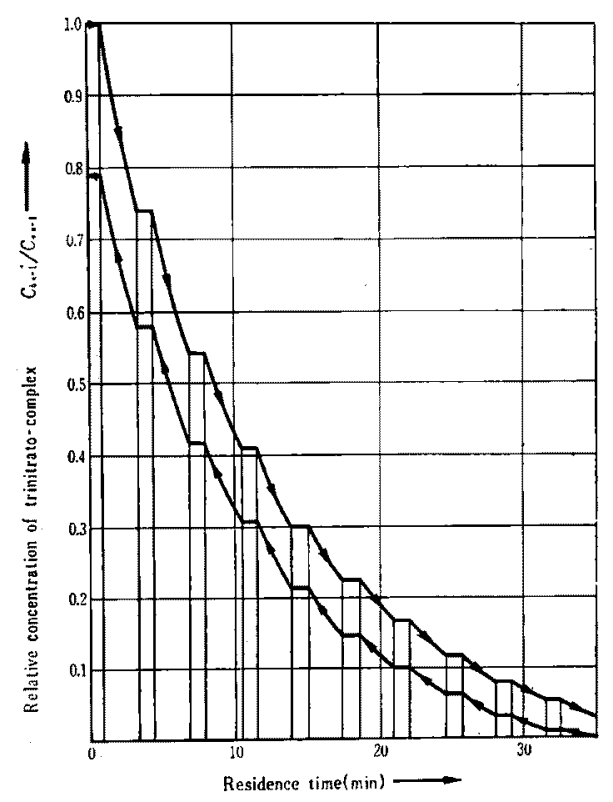

Total residence time: $35 \mathrm{~min}$ Mixing time/bank: $2.5 \mathrm{~min}$ Settling time/bank: 1 min

Fig. 6 The relative concentration of trinitrato-complex vs. residence time

tion and its results has been shown afterwards.

It should be noted here that the basic data for further understanding the practical extraction and-stripping have been established and

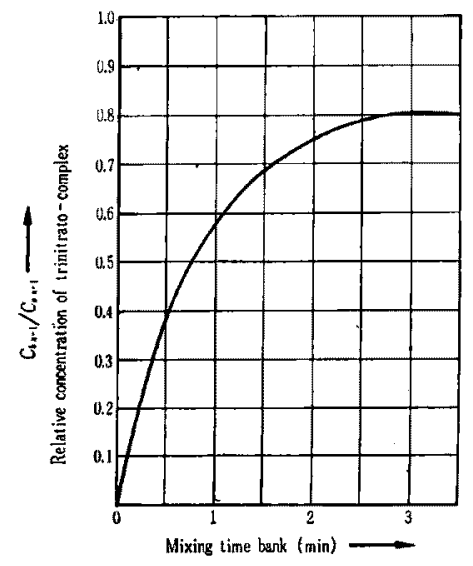

Number of stage: 10

Fig. 7 The relative concentration of trinitrato-complex in stripping vs. mixing time/bank

their I reasonable application combined with some technical data might show good agreement between practice and theory.

\section{Effects of TBP saturation with uranium}

The effects of TBP saturation with uranium have not been taken into account in the previous computation, actually uranium concentration should be, however, increased gradually in extraction section and normally $0 \sim 10 \mathrm{mgU} / \mathrm{ml}$ in the extraction section, $55 \sim 60 \mathrm{mgU} / \mathrm{ml}$ in the stripping section and at the feed stage as suggested by Williams ${ }^{(11)}$. These concentration of uranium might be assured by the computation on technical data published by Buck, et al ${ }^{00}$. The computation is shown in Fig. 8.

The competition effect of uranium might be expressed as the reduction of partition coefficient of trinitrato complex in this case. The reduction of partition coefficient of fission products vs. uranium saturation of TBP has been already published by Bruce ${ }^{(12)}$.

The reduction of partition coefficient of trinitrato complex has been also published by Fletcher ${ }^{(9)}$ who has expressed the reduction as a function of free TBP in organic phase that should be more reasonable than the expression by uranium saturation of TBP, since the partition coefficient might depend on the 


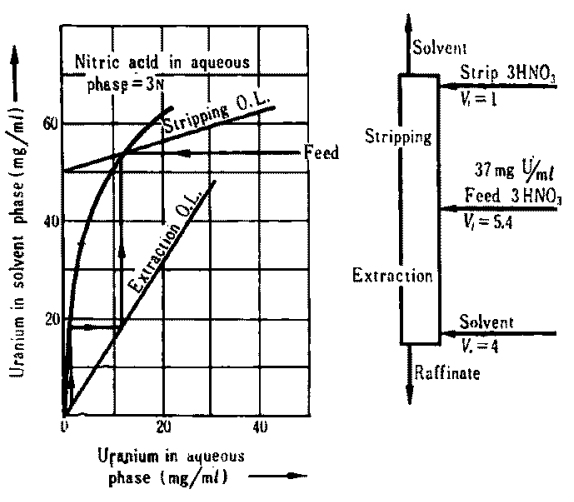

Fig. 8 Uranium concentration in extraction section

concentration of free TBP.

The experimental data of partition coefficient have been shown in Fig. 9.

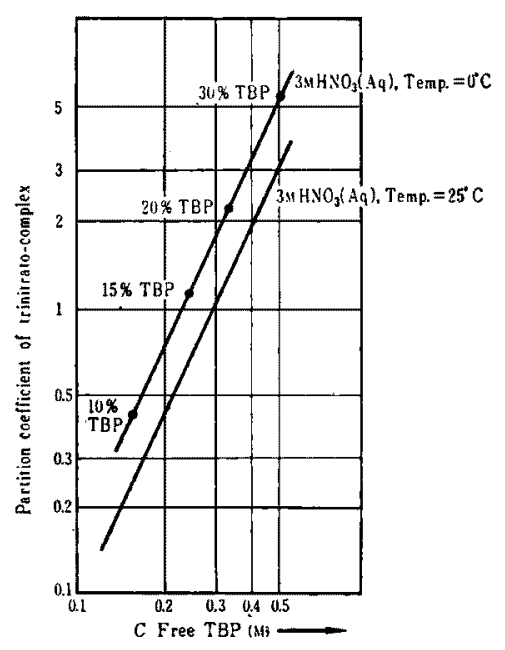

$\mathrm{CHNO}_{3}: 3 \mathrm{M}$, Temperature: $0^{\circ} \mathrm{C}$ $C_{\text {Rn }}: 3.55 \times 10^{-3} \mathrm{M}$

Fig. 9 Partition coefficient of trinitrato complex of nitrosylruthenium on free TBP concentration

The concentration of $20 \%$ TBP/OK should be $0.73 \mathrm{M}$ and the completely saturated concentration of uranium in $20 \% \mathrm{TBP} / \mathrm{OK}$ should be $87 \mathrm{mg} / \mathrm{m} l$.

The concentration of TBP loaded with 50 $\mathrm{mgU} / \mathrm{m} l$ should be,

$$
0.73 \times 50 / 87=0.42 \mathrm{M}
$$

In case of $3 \mathrm{M} \mathrm{HNO}_{3}$ in aqueous phase, and $50 \mathrm{mgU} / \mathrm{ml}$ in organic phase, the concentration of TBP loaded with nitric acid should be $0.21 \mathrm{M}$.

The concentration of free TBP should be,

$$
0.73-(0.42+0.21)=0.1 \mathrm{M}
$$

The partition coefficient of trinitrato complex 0.1 should be obtained from Fig. 9 .

\section{Relative concentration of trinitrato complex in extraction}

The concentration of uranium in organic phase might increase gradually from 0 to 10 $\sim 15 \mathrm{mgU} / \mathrm{ml}$ in the extraction section and increase directly to $50 \sim 60 \mathrm{mgU} / \mathrm{ml}$ at the feed stage as shown in Fig. 8.

If we take uranium concentration $15 \mathrm{mg}$ $\mathrm{U} / \mathrm{m} l$ at the end of extraction section, as previously described

$$
0.73 \times 15 / 87=0.126 \mathrm{M}
$$

The concentration of free TBP should be

$$
0.73-(0.126+0.35)=0.254 \mathrm{M}
$$

and then

$$
K_{T}=0.6
$$

The relative concentration of trinitrato complex would not be so much increased as 0.6 at the end of extraction, if the mixing time/bank should be decided to be sufficiently short $0.1 \sim 0.2 \mathrm{~min}$.

Otherwise, the recycling of ruthenium might occur at the stage where the relative concentration is over the partition coefficient reduced with uranium saturation of TBP.

It should be, however, quite natural that the recycling of ruthenium might always occur at the feed stage, since the relative concentration should be always over the partition coefficient remarkably reduced as already computed.

\section{Relative concentration of trinitrato complex at the feed stage}

It is not so difficult to compute the change of relative concentration $v s$. mixing time at the feed stage, since stripping Eq. (12) might be applied to it without any alteration.

It might be natural that the "mixing time should be decided to be the same to that of 
itripping section.

The typical change of relative concentraion $v s$. mixing time has been shown in Fig. 10.

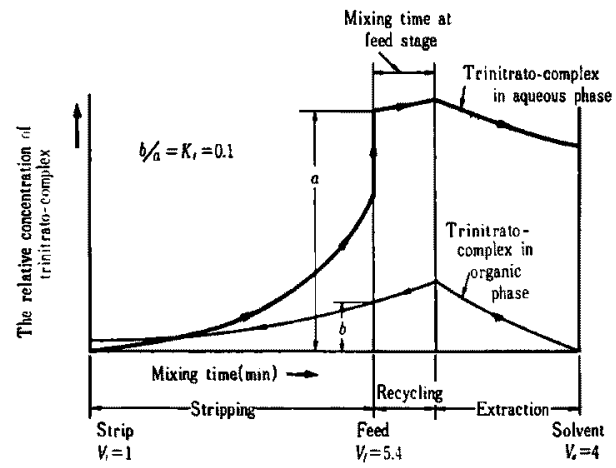

Fig. 10 The relative concentration of trinitrato complex vs. mixing time

\section{Discussion}

In the earlier computation, the following equation has been obtained,

$$
\begin{aligned}
& C_{B}=C_{B 0}\left[1-\frac{K K_{2}^{\prime}}{K_{1}^{\prime}-K_{2}^{\prime}}\left\{1-\mathbf{e}^{\left(K_{1}^{\prime}-K_{2}^{\prime}\right) t}\right\}\right] \mathbf{e}^{K_{1}^{\prime} t} \\
& =C_{B 0}\left\{\left(1-\frac{K K_{2}^{\prime}}{K_{1}^{\prime}-K_{2}^{\prime}}\right) \mathbf{e}^{-K_{1}^{\prime} t}+\frac{K K_{2}^{\prime}}{K_{1}^{\prime}-K_{2}^{\prime}} \mathbf{e}^{-K_{2}^{\prime} t}\right\}
\end{aligned}
$$

where $K=\frac{\text { Concentration of lower nitrato complex }}{\text { Concentration of trinitrato complex }}$

It has been demonstrated by the above equation that $C_{B}$ should be a complex function of $K, \mathbf{e}^{-K_{1}^{\prime} t}$ and $\mathbf{e}^{-K_{2}^{\prime} t}$.

Therefore some interactions between them should be taken into account.

At the end of extraction $\mathbf{e}^{-K_{1}^{\prime \prime} t}$ should be supressed by uranium saturation of TBP and $\mathbf{e}^{-K_{2}{ }^{\prime} t}$ might be predominant so that $K$ should be kept constant. At the middle stage and the beginning of extraction much trinitrato complex might be extracted into organic phase and the increased $K$ might restrict the further change of concentration so that the interaction between $K$ and $\mathbf{e}^{-K_{1}{ }^{\prime} t}$ might be predominant to be subjected to $\mathbf{e}^{-K_{2}^{\prime} t}$.

Therefore it might be expected that the value of $K_{2}^{\prime}$ in Eq. (5) of extraction should be somewhat bigger than 0.034 .

However, as also previously suggested by Fletcher ${ }^{(4)}$ there should exist the side reaction, of trinitrato-aquo to lower nitrato complex which is caused by the reduction of nitrate concentration, since uranium in aqueous phase should be extracted to organic phase.

The following differential equations for the side reaction have been also taken into account at the feed stage and the end of extraction section.

$$
\begin{array}{rlrl}
\frac{d C_{D}}{d t}=K_{3}{ }^{\prime} C_{B}, \frac{d C_{B}}{d t}=K_{1}{ }^{\prime} C_{B},-\frac{d C_{B}}{d t}=\left(K_{1}{ }^{\prime}+K_{3}{ }^{\prime}\right) C_{B} & \\
K_{3}{ }^{\prime} & =0.1 & t_{1 / 2} & =6 \sim 8 \mathrm{~min} \\
K_{1}{ }^{\prime} & =0.24 & t_{1 / 2} & =3 \mathrm{~min}
\end{array}
$$

After rapidly reached the equilibrium between nitrato complexes with above equations, the reduction of nitrate ion might still proceed slowly and for this reason $K_{2}{ }^{l}$ might be somewhat different from 0.034 .

\section{REMARK}

In addition to trinitrato complex of nitrosylruthenium, penta and tetra complexes have been discovered by Fletcher ${ }^{(5)}$ and it has been also suggested in his recent publication ${ }^{(13)}$ that the most extractable species, trinitrato complex in his earlier papers should correspond to penta and tetra complexes.

Therefore also trinitrato complex mostly nominated in the other earlier references and described hitherto in this script except the final TBP complex in organic phase (trinitratoTBP) should be changed to the above higher complexes, but no alteration on the computation might be expected at present.

The author wishes to thank the President and the Vice President, Atomic Fuel Corp. in Japan, for permission to publish this paper and also $\mathrm{Mr}$. T. Kawamura for his kind discussion and support on this subject.

The author also wishes to thank Dr. Y. Oyama and his colleagues, Tokyo Institute of Technology and Dr. Y. Imai, Director, Atomic Fuel Corp. in Japan, for their kind consideration on the publication.

(Received July 20, 1962)

\section{REFERENC}

(1) J. M. Fletcher, et al.: J. Inorg. Nuci. Chem.. 
1, 378 (1955).

(2) J. M. Fletcher: "Progress in Nuclear Energy", Ser. II, Vol. 1, p. 105, (1956), Pergamon, London.

(3) J. M. Fletcher : J. Inorg. Nucl. Chem., 8, 277 (1958).

(4) J. M. Fletcher, et al.: Proc. Geneva Conf., 17, 118 (1958).

(5) J. M. Fletcher, et al. : J. Inorg. Nucl. Chem., 12, 154 (1959).

(6) G. Rudstam: Acta Chem. Scand., 13, 1481 (1959).

(7) P. G. M. Brown : J. Inorg. Nucl. Chem., 13,
$73(1960)$

(8) R. M. Wallace: ibid., 20, 283 (1961).

(9) P. G. M. BROWN, et al. : AERE-C/R-2260, (1957).

(10) C. Buck, et al.: Proc. Geneva Conf., 17, 25 (1958).

(11) J. A. Williams, et al. : J. Brit. Nucl. Energy Conf., 3, 315 (1958).

(19). F. R. BRuce : Proc. Geneva Conf., 7, 108 (1956).

(13) J. M. FletCher, et al.: "Progress in Nuclear Energy", Ser. II, Vol. 3, p. 129 (1961), Pergamon London.

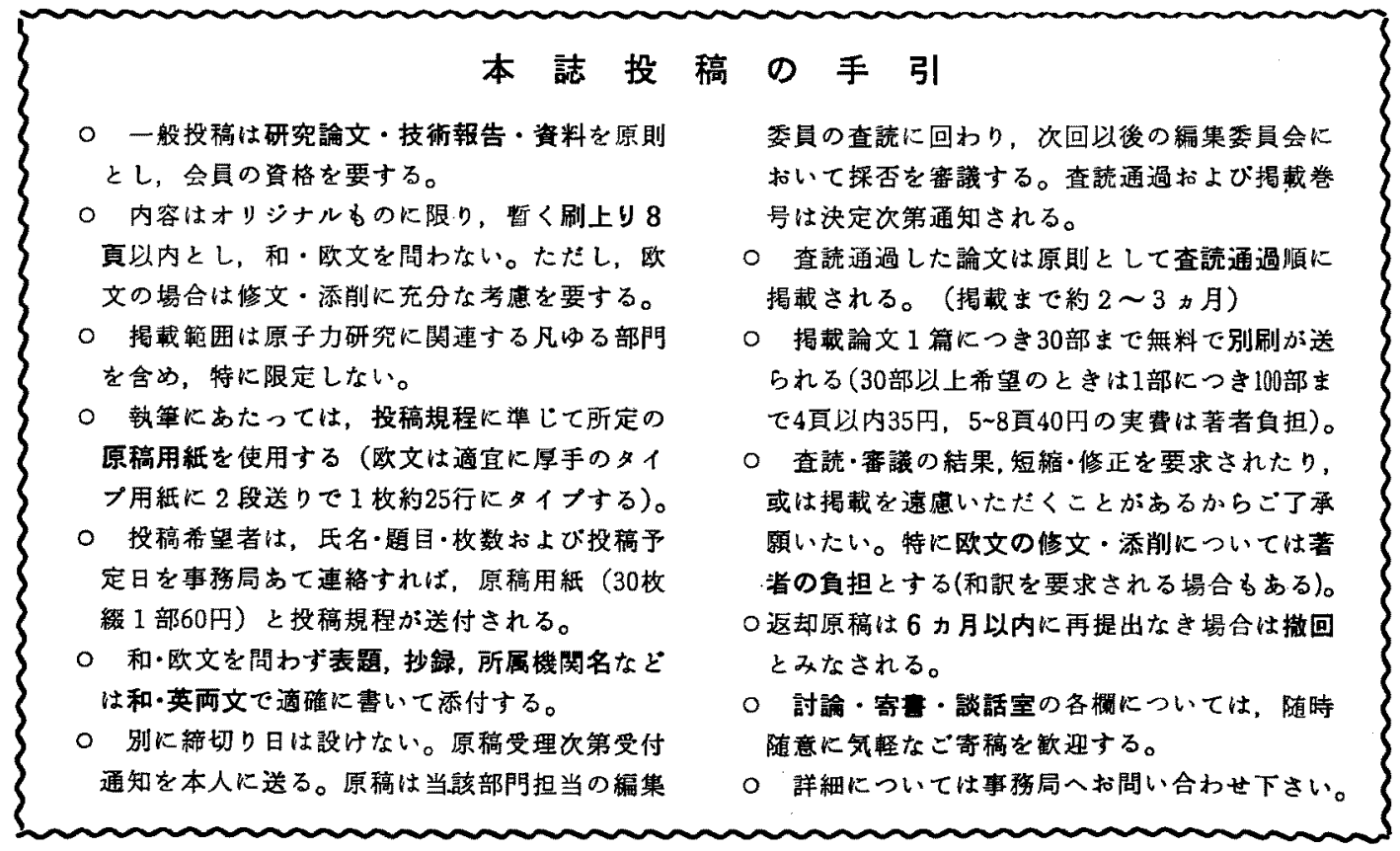

